\title{
Facilitating the interaction between theory and data in qualitative research using CAQDAS
}

Link to publication record in Manchester Research Explorer

\section{Citation for published version (APA):}

Sinkovics, R. R., \& Alfoldi, E. (2012). Facilitating the interaction between theory and data in qualitative research using CAQDAS. In G. Symon, \& C. Cassell (Eds.), Qualitative organizational research: Core methods and current challenges (pp. 109-131). Sage Publications Ltd. http://www.uk.sagepub.com/books/Book235422

\section{Published in:}

Qualitative organizational research: Core methods and current challenges

\section{Citing this paper}

Please note that where the full-text provided on Manchester Research Explorer is the Author Accepted Manuscript or Proof version this may differ from the final Published version. If citing, it is advised that you check and use the publisher's definitive version.

\section{General rights}

Copyright and moral rights for the publications made accessible in the Research Explorer are retained by the authors and/or other copyright owners and it is a condition of accessing publications that users recognise and abide by the legal requirements associated with these rights.

\section{Takedown policy}

If you believe that this document breaches copyright please refer to the University of Manchester's Takedown Procedures [http://man.ac.uk/04Y6Bo] or contact uml.scholarlycommunications@manchester.ac.uk providing relevant details, so we can investigate your claim.

\section{OPEN ACCESS}




\section{Facilitating the interaction between theory and data in qualitative research using CAQDAS}

\section{This is a pre-print (non-publisher's document). Please cite the published article:}

Sinkovics, Rudolf R. and Eva A. Alfoldi (2012), "Facilitating the interaction between theory and data in qualitative research using CAQDAS," in Qualitative organizational research: Core methods and current challenges, Gillian Symon and Catherine Cassell (Eds.). London: Sage Publications, 109-131. available: http://www.manchester.ac.uk/escholar/uk-ac-man-scw:159596

\section{Introduction}

It is generally acknowledged in the business and management literature that qualitative research tends to be 'messy'. In contrast to the typical linear structure of the quantitative research task (find or develop a theory, gather empirical data, confirm or disconfirm the theory), qualitative findings often emerge through a complex process of gradual evolution, driven by the interaction between theory and data. This iterative, cyclical process can be considered a hallmark of qualitative research. It lies at the heart of terms such as evolution of perspective (Peshkin, 1985), zipping (Orton, 1997), systematic combining (Dubois \& Gadde, 2002), cycles of deliberation (McGaughey, 2004, 2007) and the term we adopt in this chapter, progressive focusing (Parlett \& Hamilton, 1972; Stake, 1981, 1995). Our aim is to demonstrate how such an inherently 'messy' process can be made more manageable and rigorous through the use of CAQDAS. We acknowledge potential dangers in the indiscriminate and overly mechanistic use of CAQDAS (Hesse-Biber, 1996; Marshall, 2001). However, drawing on the example of a research project carried out by one of the authors, we illustrate ways to use CAQDAS in fruitful way to make non-linear research processes more systematic and add to both flexibility and rigour (Sinkovics, Penz, \& Ghauri, 2008).

First, we define what we mean by progressive focusing. The term was first noted by Parlett and Hamilton (1972), who advocated an approach where 'researchers 
systematically reduce the breadth of their enquiry to give more concentrated attention to the emerging issues' (Parlett \& Hamilton, 1972, p.18). This perspective was taken up and refined by Stake $(1981,1995)$ who described progressive focusing as follows:

'Progressive focusing requires that the researcher be well acquainted with the complexities of the problem before going to the field, but not too committed to a study plan. It is accomplished in multiple stages: first observation of the site, then further inquiry, beginning to focus on the relevant issues, and then seeking to explain.' (Stake, 1981, p.1)

With its emphasis on pre-fieldwork preparation and openness to emergent issues from the field, we find this description sets a useful example for qualitative research. We use the concept of progressive focusing to extend and refine the linear model of the qualitative research process commonly depicted in the literature (see Eisenhardt, 1989; Iacobucci \& Churchill, 2010; Sinkovics et al., 2008; Yin, 2003). Hence, the key distinguishing feature of our model (shown in Figure 1) is the iterative and repeatable nature of its component steps.

Insert Figure 1 about here

Step 1 of the research task encompasses several key tasks facing the researcher at the start of a new research project: choosing a topic and conducting a literature review, in order to build the theoretical and conceptual foundations of the research. This step includes the articulation of basic assumptions, logic and expectations, as well as developing the research questions - a task that is closely intertwined with the literature review, since research questions should be clearly rooted in the theoretical foundations and literature gaps identified through a review of existing research.

Step 2 focuses on the logic behind operationalising the research questions. The researcher draws up a 'blueprint', seeking a good fit between theoretical foundations, epistemological assumptions and practical feasibility issues. Building sound logic and coherent ideas, with the input of fellow academics, forms an essential part of this step.

Building on the first two steps, Step 3 is concerned with moving the research 'out of theory and into the field' by carefully choosing a sample and a context. Admittedly, in many cases, sampling and context are influenced by pragmatic issues such as pre-existing contacts or ease and level of access - as a result, Step 3 could 
involve prolonged negotiations, or alternatively even precede Step 1.

Once the first three steps have been taken, it is time for the researcher to enter the field in earnest. Step 4 contains the task of collecting and preparing primary data, whilst Step 5 consists of analysing that data and embedding it in what is known from the literature or other (often secondary) data sources. In our model, these steps are tightly linked not only with each other, but also with Step 1. The arrows linking Steps 1, 4 and 5 highlight the constant comparison of data with literature, a key aspect of a grounded approach (see Glaser \& Strauss, 1967; Strauss \& Corbin, 1998).

We argue that this constant comparison has considerable potential to influence the completion of the research task. If the data - collected in Step 4 and analysed in Step 5 - is found to have sufficient fit with the theoretical and conceptual framework and research questions developed in Step 1, the researcher may move on to Step 6, which involves developing and articulating the key arguments and overall contributions of the research. However, the analysis in Step 5 may reveal that the data does not fit sufficiently with the framework and questions developed in Step 1; or it may expose previously unconsidered emic constructs ${ }^{1}$ that are of particular interest to the research and require further investigation. In such cases, it may make sense to return to the field for more data, and/or return to the literature to refine the underlying theoretical and conceptual foundations. Depending on the complexity of the data, the researcher's interpretations and the emergent theoretical framework, any or all of Steps 1, 4 and 5 may be repeated before finally moving on to Step 6. The goal of theoretical saturation (Glaser \& Strauss, 1967; Strauss \& Corbin, 1998) and practical constraints (such as interviewees' availability) mean that researchers may end up alternating between the three steps until such a point where they are satisfied that their theoretical focus, empirical data and potential contribution are in line with one another. The point at which this is achieved - and thus the number of iterations between Steps 1, 4 and 5 that are required - may differ widely across research projects. Whilst the optimal number of iterations cannot be prescribed ex ante, the process can be managed in a systematic manner through the use of CAQDAS.

In our terminology, etic refers to constructs that are developed by the researcher and take an outside view of the phenomenon under investigation, whilst emic refers to native constructs emerging from inside the research setting and reflecting the insider's view of reality (see Buckley \& Chapman, 1997; Sinkovics et al., 2008). 


\section{The role of CAQDAS in the qualitative research process}

We believe that the research model described above is helpful in capturing the 'true' nature of qualitative research and makes a contribution to increasing the legitimacy and acceptance of the 'messiness' of qualitative research (Mellor, 2001). However, we also recognise the inherent danger that a call for acknowledging flexibility and progressive focusing in qualitative research may be misinterpreted as a call for leniency towards unsystematic research, at a time when qualitative research is rife with accusations of lack of rigour, the apparent misuse of concepts such as grounded theory and opacity in describing research methodology (Jones \& Noble, 2007; Suddaby, 2006). In order to tackle these kinds of criticism, we encourage the use of CAQDAS during each of the six steps in our model. We believe that using CAQDAS can accommodate the non-linear and evolving process of interaction between qualitative data and the theoretical and conceptual backbones of research, whilst also helping in the operational management and formalisation of the research.

The term CAQDAS can refer to various types of software designed to facilitate the analysis of qualitative data. Weitzman and Miles (1995) originally developed a typology concerning the handling and management of qualitative (then, mostly textual) data, formerly labelled code and retrieve software and the more extensive functionality in code-based theory builders. However, the boundaries between these types of software have become increasingly blurry and nowadays most modern CAQDAS packages handle data beyond text, i.e. graphics, audio and video, and offer tools that enable content searching tools, linking, coding, querying, writing and annotation, and often also mapping and networking (Lewins \& Silver, 2007, 2009).

We believe that the acronym 'CAQDAS' is somewhat of a misnomer: to the untrained ear, 'Computer-Assisted Qualitative Data Analysis Software' may convey an inappropriate sense of the software taking over the analytical process. It has long been recognised that such software was never intended to replace the researcher's unique skills in analysing and interpreting complex data (Catterall \& Maclaran, 1998; Gordon \& Langmaid, 1988; Gummesson, 2005). Instead, CAQDAS is designed to facilitate the organisation and processing of data and enhance the dialogue between researcher and data. As such, it is a meritorious tool that helps in legitimising the 
acknowledgement of complexity and 'messiness' in the reporting of qualitative research, whilst also encouraging greater transparency, credibility and trustworthiness (Ghauri \& Firth, 2009; Sinkovics, Penz, \& Ghauri, 2005; Sinkovics et al., 2008).

CAQDAS provides a toolset for the analysis of abundant qualitative data that can be understood similar to decision support systems used by practitioners (Shim et al., 2002). Following Little's decision calculus, we believe qualitative research can benefit from a 'set of procedures for processing data and judgements to assist [...] in decision making' (Little, 1970). These procedures are to be 'simple, robust, easy to control, adaptive, complete on important issues and easy to communicate' (Little, 2004, p.1855). When used appropriately, CAQDAS allows qualitative researchers to have a 'dialogue with the computer' and develop a greater degree of effectiveness and rigour at each step of the research process. This is achieved through documenting the interactive process of going forwards and backwards between theory and the field.

By creating an auditable 'footprint' of the progressive dialogue between the researcher and their data, CAQDAS can help researchers define the space in between the two opposing views that dominate qualitative research debates: the highly inductive grounded theory approach promoted by Glaser (Glaser, 1992; Glaser \& Strauss, 1967), and the highly structured, deductively oriented qualitative analysis advocated by Eisenhardt (1989) and Yin (2003). In essence, the debate between these opposing views is a debate about the relative importance of creativity versus formalisation, of meaning versus validity. We believe that the two are equally important and achievable through an emphasis of strong research logic, flexibility and thorough documentation. In particular, CAQDAS can assist qualitative researchers in managing each step of the research process and in making their methodology more accessible to peers and reviewers.

As a caveat, it should be noted that, like any other tool, CAQDAS can be used well or used badly. It is up to the individual researcher - and those involved in their training and guidance - to ensure that expectations are appropriate and realistic. CAQDAS is neither a shoehorn for forcing grounded research into a set of mechanistic criteria, nor a cover-all for superficial research. We urge researchers to acknowledge the fluidity and 'moving goalposts' that characterise qualitative research, but we also encourage careful and detailed documentation of this process. Many qualitative researchers - particularly those new to academia - fear that by 
closely documenting unexpected twists and turns of their research, they are laying themselves open to criticism. Nonetheless, it should be recognised that in qualitative research, the realistic purpose of a systematic audit trail is not to ensure replicability, but precisely to explain the idiosyncrasies of each qualitative research project that preclude replicability. As such, we argue that CAQDAS can enable the production of robust and defensible qualitative research that can stand up to close scrutiny.

\section{Methodology and application to data}

In this section, we use the example of case study research conducted by one of the authors (Alfoldi, 2008) to illustrate the practical application of CAQDAS (in particular, the NVivo software) ${ }^{2}$ during each step of the progressive focusing model in Figure 1. The research consists of a single in-depth case study of knowledge transfer and regional governance in a large multinational firm, and is briefly described next.

\section{Timeline of the qualitative research project}

The research project started with a 'preparatory' phase that encompassed Steps 1, 2 and 3 of the model presented in Figure 1. Step 1 began with a thorough review of theories of the multinational enterprise, subsidiary management, knowledge transfer and management and organisational learning. Based on this, research questions were developed concerning the nature of knowledge transfer in multinational companies, with particular focus on two constructs: reverse knowledge transfer (knowledge created at the subsidiary, then transferred to headquarters (HQ)) and secondary knowledge transfer (subsidiaries adapting knowledge received from HQ and transferring it to other subsidiaries in the intra-company network). Given the scarcity of extant research on these types of knowledge transfer and the exploratory nature of the research questions, a qualitative case study methodology was designed in Step 2, based on a social constructionist epistemology. In Step 3, pilot interviews were conducted at the Hungarian subsidiaries of three multinational companies that the researchers had negotiated access to. Only one of the three subsidiaries indicated extensive ongoing links with other subsidiaries, which was a vital prerequisite for the

As noted before, several different kinds of CAQDAS tools are available for qualitative researchers. We use NVivo (Richards, 2005) for pragmatic reasons, rather than to advocate utilisation of a specific software package over alternative software. Nonetheless, NVivo offers a number of features (such as collaborative and merge features) which are particularly helpful in the coordination of international fieldwork. 
research topic, so a single in-depth case study was chosen as the research method.

Step 4 of the research process involved conducting several interviews at the Hungarian subsidiary of the focal company. Faced with the considerable size and complexity of the subsidiary's overall operations, the empirical focus was narrowed to a specific functional division, trade marketing, which focuses on marketing the company's products and services to retail customers rather than consumers. In Step 5, the rich data generated from these interviews was analysed in depth, which revealed a complex, formal regional hierarchy between the company's Hungarian unit and two other subsidiaries in Slovenia and Croatia. These findings inspired a return to Step $\mathbf{1}$ of the research process: and conducting a literature review of previously unexamined theoretical areas such as regional integration and responsiveness (Lehrer \& Asakawa, 1999) and subsidiary mandates (Birkinshaw, 1996). It also fostered theorising about new constructs such as regional administrative mandates.

This was followed by a return to Step 4, in the form of a second set of interviews at the company's units in Slovenia and Croatia. The analysis of this new data (Step 5) not only provided an alternative empirical perspective on the issues investigated so far, but also highlighted the relevance of related constructs such as inter-unit ties (Hansen, 1999), corporate socialisation (Björkman, Barner-Rasmussen, $\& \mathrm{Li}, 2004)$ and motivation for knowledge sharing (Osterloh \& Frey, 2000). This in turn triggered going back to Step 1 again to conduct a literature search for conceptual links with knowledge transfer and regional management.

Inspired by the findings and constructs emerging from the data as well as from the newly explored strands of literature, a third and fourth set of interviews was carried out face-to-face and over the telephone (repeating Step 4 twice more). These interviews followed up and extended the findings to another division, marketing, which was emerging as a useful contrast to the trade marketing division in terms of reporting structure and knowledge transfer links. The new data also provided insights suggesting the presence of role stress (see Wong, DeSanctis, \& Staudenmayer, 2007) as a factor in the units' difficulties in sharing knowledge effectively. This prompted an investigation of the role stress literature and its links to knowledge transfer (Step 1), as well as a careful re-examination of previously collected data for references implying role stress (Step 5). There was also some hard-won input from the company HQ on wider regional perspectives, but not enough to justify a continued focus on 
HQ-subsidiary knowledge transfer without the danger of biased representation. As such, the research had to be refocused entirely on the subsidiary perspective, necessitating another return to Step 1, as the 'natural boundaries' of the case were discovered (and to a certain extent, imposed) in a progressive manner. By this point, the theoretical and empirical analysis was finally indicating a degree of theoretical saturation that was deemed sufficient to embark on Step 6: a final write-up articulating and synthesising the arguments and contributions of the research.

This account illustrates the emergent and idiosyncratic nature of the typical qualitative research process, highlighting the repeated interaction between theory and data that is the hallmark of progressive focusing. Next, we address each step in turn to show how CAQDAS can be used to facilitate this complex process of interaction.

\section{Application of CAQDAS during each step of the research process}

In this section, we use specific examples from the project described above to illustrate how CAQDAS may be used to manage and document rich data and complex analytical processes during each of the six steps of the progressive focusing model.

\section{Step 1: Choosing a topic, literature review, development of theoretical and conceptual foundations and research questions}

One of the first tasks facing a researcher embarking on a new project is creating a title for the intended contribution. A good title serves a dual purpose: it communicates the researcher's intent to others, but more immediately, it also shapes the researcher's own thinking by temporarily demarcating the boundaries of the core topic (Peshkin, 1985). As we have argued, the focus and perspective of qualitative research evolve progressively, so the title of a qualitative study rarely stays constant throughout the research process. Peshkin (1985) recommends filing and dating each version of the title, in order to allow the researcher to reconstruct the evolution of key perspectives and conceptual drivers and to aid as well as evaluate progress. Although this may be achieved by saving several word-processed drafts of the research, the evolution of the title can be more formally and reliably documented via the use of CAQDAS such as NVivo (Richards, 2005). We advocate filing and dating successive versions of the title as well as the evolving research questions (see Andersen \& Skaates, 2004) in the form of a project memo, which allows the progression of the researcher's thinking and intended contribution to be documented and tracked. 
During the first step of the qualitative research process, the researcher's principal task is to conduct a thorough, critical and rigorous literature review. Such a review is crucial for building up a robust theoretical basis for the study, accurately defining a gap in the literature and developing the core topic and research questions of the study. In the business and management discipline, narrative reviews are the norm, which are singular descriptive accounts of the contributions made by writers in the field, often selected for inclusion on the implicit biases of the researcher' (Tranfield, Denyer, \& Smart, 2003, p.208). Narrative reviews can appear subjective and arbitrary when compared with the systematic reviews found in medical science and healthcare. Systematic reviews observe a strict 'hierarchy of evidence' (Davies \& Nutley, 1999; Tranfield et al., 2003) and use explicit procedures for including or excluding previous studies, in order to minimise bias and error. However, the soft, applied, rural and divergent nature of business and management research (Tranfield \& Starkey, 1998) often precludes this kind of systematic approach. Whilst quantitative studies in business and management may lend themselves to meaningful meta-analysis, qualitative studies are generally ill-suited to this purpose - the sheer diversity in methodologies and contextual idiosyncrasies makes reliable comparisons and quality assessments very difficult.

Nonetheless, even if fully systematic literature reviews are not achievable in qualitative business and management research, we feel there is room for enhancing the credibility of narrative reviews. Greater rigour can be achieved by meticulously documenting literature searches, keeping a record of keywords and key arguments, and systematically extracting information to build a 'casebook' of references, through a process of descriptive coding (Richards, 2005). For example, during the research project we described above, a list of the key journal articles related to regional management in multinational companies was compiled by importing abstracts and document links into NVivo and coding them as individual cases. A number of key attributes were defined (journal star rating, study methodology etc.) and values were assigned for each case. This approach not only allowed the researcher to keep a reliable, searchable record of the literature used, but also enabled a matrix data display (see Miles \& Huberman, 1994) of the articles in NVivo and filtering by attributes. 
Insert Figure 2 about here

Figure 2Looking at Figure 2, multiple case studies appear to be the dominant empirical research method in the area of regional management. Insights such as this can facilitate more robust and credible arguments about the state of the art in the field than anecdotal citations alone. In addition to enhancing credibility, casebooks also make it easier to find pre-existing measurements and remain alert to the background assumptions of the research (see Potter, 1996). The initial time outlay on importing abstracts and assigning attributes can be more than compensated by the benefits of an organised, searchable database of theoretical inputs which can be coded and constantly compared with the empirical data. We recommend using Endnote (Thomson Reuters, 2010) and NVivo concurrently to manage references and document the development of the theoretical foundations of the study.

\section{Step 2: Research design}

The aim of Step 2 is to develop a robust research design that fits the underlying research questions and logic. This should be underpinned by a sound understanding of the relevant epistemological conventions and the explicit articulation of what the study is trying to achieve. Source materials on methodology can be catalogued in NVivo in much the same way as items in the theoretical literature review (see Section 0). This makes it easier to search for specific references, keywords or arguments when discussing the suitability of, and justifications for, a particular research design. Importing abstracts of methodological and empirical papers within the same NVivo project file and filtering them by attributes also allows quick and systematic access to exemplars, i.e. side-by-side comparison of how other researchers have applied a specific methodology or technique in a given context. This facilitates comparisons and encourages ongoing awareness of how the developing research design fits with the designs used in previous research. In addition, NVivo's modelling function can be used to visualise various aspects of the research design, and external documents such as drawings and sketches can be linked to a central 'hub'. All of these help the researcher to keep more reliable records and cultivate a clearer and more rigorous approach to methodology. 


\section{Step 3: Sample, context and negotiating access}

Although theoretical sampling, choosing a suitable research context and negotiating access tend to be largely 'hands-on' tasks, the organising capabilities of CAQDAS such as NVivo may also prove useful during this step. In particular, first impressions and observations during access negotiations and initial rapport-building with specific companies or respondents can prove a rich source of useful data later on (Lee, 1999). NVivo allows observations, notes and e-mail conversations to be recorded in memos, which can be linked to documents and coded alongside other items. For example, if a gatekeeper at a company expresses a specific concern or attitude during the initial access negotiations, or offers an insight into the organisational structure of the company, this can be noted and stored in memos and linked to other materials. Such memos may inform the approach taken during subsequent data collection, or provide vital clues and insights during data analysis. In this sense, we argue that by helping the researcher capture and file away potentially important details from the outset, the data storage and organisation capabilities of CAQDAS can even facilitate 'Eureka!' moments.

With regards to choosing and managing the context of the research, NVivo can be particularly useful for cross-cultural or inter-industry comparative studies where empirical data is collected from different sources. Firstly, it allows the researcher to collate and code information about multiple contexts (e.g. country or company statistics from secondary sources) and document the selection of context(s) in a transparent manner, e.g. by using the modelling function to build decision trees. Secondly, once a particular research context has been chosen, the existing materials stored in NVivo can be regularly updated or supplemented with new information (such as press cuttings, company press releases or industry analysis reports).

\section{Step 4: Data collection and preparation}

During this step, Andersen and Skaates (2004) advocate creating a diary for tracking emergent themes and changes in theoretical focus, a task that can be greatly assisted by the use of CAQDAS. There are a number of ways to collate data from primary sources in a single place using NVivo. Word-processed data such as interview transcripts can be directly imported into the project file; observations can be recorded in memos; and visual or aural data (sketches drawn by interviewees, 
photographs, voice files etc.) can be linked to the project file externally. Data sources such as interviews can be coded as cases and directly compared in a data matrix (see Section 0). Figure 3 shows an example of creating and assigning key attributes (such as respondent nationality, functional division etc.) to each interview and charting the cases according to certain attribute values.

Insert Figure 3 about here

In Figure 3, the chart shows the overall distribution of respondents according to their official work level in the company. It can be seen that most interviews were conducted with respondents at the middle manager level (WL3 in the case company), followed by operational-level managers (WL2), country group-level directors (WL4), junior employees (WL1) and finally regional or HQ-level directors (WL5). Since middle managers are often seen as critical 'roadblocks' for transferring knowledge within multinational companies (Mäkelä \& Seppälä, 2005), charts like these can be used as a gauge between periods of data collection to decide which 'snowballing' leads (Patton, 1990) to follow and what level of respondents to approach next, given resource and access constraints. The ability to keep track of the balance of respondents, maintain searchable descriptive casebooks and chart them according to researcher-defined attributes using CAQDAS can be especially useful for large projects with considerable diversity amongst respondents.

\section{Step 5: Data analysis}

Out of all six steps of the qualitative data analysis process, data analysis is perhaps the most obvious task to benefit from the application of CAQDAS such as NVivo, and a lot has been written about the use of CAQDAS for data analysis (see e.g. Ghauri \& Firth, 2009; Lindsay, 2004; Maclaran \& Catterall, 2002; Sinkovics et al., 2005). During this step, the competent and systematic use of software such as NVivo can strengthen trustworthiness by establishing a chain of evidence (Yin, 2003) that truthfully represents the formalised tasks contained in the process of data analysis: organising and coding the data, searching for patterns and modelling emergent frameworks. By systematically linking and organising multiple sources of data, it can also aid in tackling the problem of anecdotalism that qualitative research 
often suffers from (Silverman, 2005). As noted already in Step 1, NVivo can greatly assist the constant comparison or triangulation between theory and data (Denzin, 1989; Strauss \& Corbin, 1998) and allow the researcher to effectively manage the alternating sequences of data collection and analysis which are the hallmarks of progressive focusing. Using CAQDAS enables the documentation of the ongoing evolution of complex and closely interlinked components of the study, such as the interview protocol and the study's key constructs and themes, be they etic or emic. Perhaps most importantly, NVivo is a useful platform for formally articulating and defining codes and themes that form the backbone of qualitative data analysis.

There are two basic strategies for analysing qualitative data: topic coding and analytical coding (also known as axial coding, see Strauss \& Corbin, 1998). Topic coding refers to the coding of material into a subject-based structure and is recommended as the first step in the formal analysis of newly gathered data (Richards, 2005). It follows a primarily grounded, data-driven logic: its main purpose is to allow the researcher to make sense of the rich, complex data collected during fieldwork and create an organised record of all the themes in the data that are considered (potentially) illuminating. In contrast, analytical coding refers to coding the data into an evolving structure based upon the analyst's ongoing interpretation of the action (Richards, 2005). As such, analytical coding relies heavily on the theoretical and conceptual inputs into the research, in addition to the empirical data. Since analytical coding is structured around the intended contribution of the study, its purpose is to generate a refined, integrated and theorised coding scheme, building on the outputs of the topic coding process and the progressive interaction between theory and data. Therefore, both of the above coding strategies form an integral part of qualitative data analysis (Richards, 2005).

In our example, the cyclical process of going back and forth between the theoretical foundations of the study and the field yielded emergent themes and constructs that were significant both in their number and in their influence on the study (a number of these constructs were already noted in Section 0). Figure 4 shows two versions of the evolving topic coding scheme from different phases of the research process. The first version consists of 37 codes which include contextual information about the company (operations, trade marketing function, reporting lines), and focus primarily on the construct of knowledge transfer, the main theoretical driver 
of the research. There is also an early conceptualisation of subsidiary mandates, broken down into management mandates and knowledge transfer-related mandates.

Insert Figure 4 about here

Tracing these constructs to the second version of the coding scheme, created several months later, we find not only more references (thanks to the growing number of interviews conducted) but also more codes (93 in total). Subsidiary mandates are now conceptualised in more detail, incorporating formal task classifications from the literature. The construct of knowledge transfer is elaborated in detail and whilst the codes are still primarily descriptive (making sense of the data), they now include new conceptual aspects such as the level of formality. Meanwhile, contextual codes like company operations no longer occupy a prime position - nonetheless, having captured them in the early version of the topic coding scheme allowed the researcher to build a thorough company introduction section in the finished piece.

The final column in Figure 4 shows the analytical coding scheme developed during the latter stages of the research project, which consists of 30 final codes. These codes are built on the previous topic codes, but are structured around the intended contribution of the research: as such, they no longer include certain emergent constructs such as subsidiary mandates (which subsequently formed the basis of a different publication) but expand on other emic constructs such as types of role stress. Descriptive constructs such as knowledge transfer types (originating from the data) have been absorbed into constructs such as communication frequency, corporate socialisation and motivation for knowledge transfer (embedded in the literature). As such, the final analytical coding scheme represents an intricately fused version of etic and emic insights, of theory and data, formed through repeated interaction between newly acquired data and newly explored literature streams during the project.

The ability to save these evolving versions of the coding scheme within NVivo provided crucial assistance in documenting the ongoing development of the analysis and interpretation of empirical data, signposting as well as facilitating the progressive focusing approach taken in this study. Our example demonstrates the major role that CAQDAS can play during this step of the qualitative research process. 


\section{Step 6: Discussion and final write-up}

It has been argued that the central problem of presenting qualitative findings is the lack of accessibility to the interpretation process itself (Andersen \& Skaates, 2004, p.479). To an extent, this problem can be alleviated by careful attention to the explanation and illustration of research methodology in the final output. The inclusion of examples of data displays and coding schemes, as well as a clear and consistent explanation of the procedures followed during each step of the research process can go a long way to enhancing the credibility and authenticity of the research, without obscuring or distorting the nonlinear nature of the process. To this end, CAQDAS can play a significant role in constructing the methodology section of the final research report. In addition, the logic and contribution of the study must be explicitly summarised and embedded within the literature, with special attention to any contradictions between the study's findings and previous research (Andersen \& Skaates, 2004). During this step, having a well-documented, searchable record of each step of the research process can be a vital tool for insightful discussion and thoughtful evaluation of the research findings. In the case of cross-border research teams, NVivo's merge function can facilitate and simplify the writing-up task by synchronising research materials (Sinkovics et al., 2008).

\section{Conclusion}

This chapter argues that the use of CADQAS such as NVivo can facilitate the qualitative research process and enhance the trustworthiness of qualitative research (Sinkovics, 2009; Sinkovics et al., 2008). This can be achieved in two ways: (1) by assisting the interaction of theoretical and empirical inputs into the research; and (2) by laying down an audit trail or chain of evidence (Yin, 2003). Our experience is that, if used appropriately, CAQDAS can enable a logical and systematic approach without constraining the emergent nature of qualitative data collection and analysis. Through systematising and documenting the research process, CAQDAS may be seen as a way to strengthen the trustworthiness and rigour of reporting qualitative research, without constraining its flexibility.

Despite concerns about CAQDAS fostering a temptation to quantify, fragment or over-simplify qualitative research (Bryman \& Bell, 2003; Jack \& Westwood, 
2006), our experience leads us to concur with Kelle (1997) that these dangers have been exaggerated. Through the empirical example provided in this chapter, we have not only demonstrated the progressive focusing process of a typical qualitative research project, but also showed how CAQDAS can be used to open up dialogues and interaction between human and computer (Little, 2004) and enhance the credibility of research through systematisation and record-keeping (Ghauri \& Firth, 2009; Sinkovics et al., 2005, 2008). We argue that, far from obscuring the inherently 'messy' and constantly evolving nature of qualitative research, CAQDAS can be used to facilitate the analysis of large volumes of data through systematic comparison with theory. The role of CAQDAS in this fluid and dynamic interaction between theory and data is to aid a more formalised process that potentially makes qualitative inquiry more logical, transparent and trustworthy. To this end, we hope that this chapter contributes to overcome the artificially linear reporting of qualitative research towards a more 'real-world' presentation, whilst also observing requirements of rigour and trustworthiness in data and reporting.

\section{Further reading}

Denzin, Norman K., \& Lincoln, Yvonna S. (Eds.). (1994). Handbook of qualitative research. Thousand Oaks, CA.: Sage Publications.

Kirk, Jerome, \& Miller, Marc L. (1986). Reliability and validity in qualitative research. Newbury Park, CA: Sage Publications.

Lincoln, Yvonna S., \& Guba, Egon G. (2002). Judging the quality of case study reports. In A. Michael Huberman \& Matthew B. Miles (Eds.), The qualitative researcher's companion (pp. 205-216). Thousand Oaks: Sage Publications.

Parkhe, Arvind. (1993). 'Messy' research, methodological predispositions, and theory. Academy of Management Review, 18(2), 227-268.

Seale, Clive. (1999). The quality of qualitative research. London: Sage Publications.

Van Maanen, John. (1998). Different strokes: Qualitative research in the administrative science quarterly from 1956 to 1996. In John Van Maanen (Ed.), Qualitative studies of organizations (pp. ix-xxxii). Thousand Oaks: Sage Publications.

\section{Acknowledgments}

The authors gratefully acknowledge the editorial guidance and support of Gillian Symon and Catherine Cassell, who significantly helped to sharpen and focus this contribution. We are also indebted to L. Jeremy Clegg and Sara McGaughey, both of whom have helped to uplift the execution of the empirical project. Finally, insightful comments from Brandon Charleston have triggered some of the systematisation 
arguments, upon which this chapter hinges.

\section{References}

Alfoldi, Eva A. (2008). Knowledge transfer in the multinational enterprise: The impact of inter-subsidiary hierarchy and role stress. University of Leeds, Leeds.

Andersen, Poul Houman, \& Skaates, Maria Anne. (2004). Ensuring validity in qualitative international business research. In Rebecca Marschan-Piekkari \& Catherine Welch (Eds.), Handbook of qualitative research methods for international business (pp. 464-485). Cheltenham: Edward Elgar.

Birkinshaw, Julian. (1996). How multinational subsidiary mandates are gained and lost. Journal of International Business Studies, 27(3), 467-495.

Björkman, Ingmar, Barner-Rasmussen, Wilhelm, \& Li, Li. (2004). Managing knowledge transfer in MNCs: The impact of headquarters control mechanisms. Journal of International Business Studies, 35(5), 443-455.

Bryman, Alan, \& Bell, Emma. (2003). Business research methods. Oxford: Oxford University Press.

Buckley, Peter J., \& Chapman, Malcolm. (1997). The use of native categories in management research. British Journal of Management, 8(4), 283-299.

Catterall, Miriam, \& Maclaran, Pauline. (1998). Using computer software for the analysis of qualitative market research data. Journal of the Market Research Society, 40(3), 207-222.

Davies, Huw T. O., \& Nutley, Sandra M. (1999). The rise and rise of evidence in health care. Public Money \& Management, 19(1), 9-17.

Denzin, Norman. (1989). The research act. Englewood Cliffs: Prentice Hall.

Dubois, Anna, \& Gadde, Lars-Erik. (2002). Systematic combining: An abductive approach to case research. Journal of Business Research, 55(7), 553-560.

Eisenhardt, Kathleen M. (1989). Building theories from case study research. Academy of Management Review, 14(4), 532-550.

Ghauri, Pervez N., \& Firth, Rebecca. (2009). The formalization of case study research in international business. der Markt, 48(1), 29-40.

Glaser, Barney. (1992). Basics of grounded theory analysis: Emergence vs forcing. Mill Valley, CA: Sociology Press.

Glaser, Barney G., \& Strauss, Anselm. (1967). The discovery of grounded theory: Strategies of qualitative research. London: Wiedenfeld and Nicholson.

Gordon, Wendy, \& Langmaid, Roy. (1988). Qualitative market research: A practitioner's and buyers guide. Aldershot: Gower.

Gummesson, Evert. (2005). Qualitative research in marketing: Road-map for a wilderness of complexity and unpredictability. European Journal of Marketing, 39(3/4), 309-327.

Hansen, Morten T. (1999). The search-transfer problem: The role of weak ties in sharing knowledge across organization subunits. Administrative Science Quarterly, 44(1), 82-111.

Hesse-Biber, Sharlene. (1996). Unleashing frankenstein's monster? In Robert Burgess (Ed.), Studies in qualitative methodology: Computing and qualitative research (Vol. 5, pp. 25-41). London: JAI Press. 
Iacobucci, Dawn, \& Churchill, Gilbert A. (2010). Marketing research: Methodological foundations (10th ed.). Mason, Ohio: South-Western Cengage Learning.

Jack, Gavin, \& Westwood, Robert. (2006). Postcolonialism and the politics of qualitative research in international business. Management International Review, 46(4), 481-500.

Jones, Robert, \& Noble, Gary. (2007). Grounded theory and management research: A lack of integrity? Qualitative Research in Organizations and Management, 2(2), 84-103.

Kelle, Udo. (1997). Theory building in qualitative research and computer programs for the management of textual data. Social Research Online, 2(2), http://www.socresonline.org.uk/2/2/1.html.

Lee, Thomas W. (1999). Using qualitative methods in organizational research. Thousand Oaks: Sage Publications.

Lehrer, Mark, \& Asakawa, Kazuhiro. (1999). Unbundling european operations: Regional management and corporate flexibility in American and Japanese MNCs. Journal of World Business, 34(3), 267.

Lewins, Ann, \& Silver, Christina. (2007). Using software in qualitative research: A step-by-step guide. London: Sage Publications.

Lewins, Ann, \& Silver, Christina. (2009). Choosing a CAQDAS package. Retrieved Oct 21, 2010, from http://eprints.ncrm.ac.uk/791/1/2009ChoosingaCAQDASPackage.pdf

Lindsay, Valery J. (2004). Computer-assisted qualitative data analysis: Application in an export study. In Rebecca Marschan-Piekkari \& Catherine Welch (Eds.), Handbook of qualitative research methods for international business (pp. 468506). Cheltenham, UK: Edward Elgar.

Little, John D. C. (1970). Models and managers: The concept of a decision calculus. Management Science, 16(8), B466-B485.

Little, John D. C. (2004). Comments on "models and managers: The concept of a decision calculus": Managerial models for practice. Management Science, 50(12), 1841-1853.

Maclaran, Pauline, \& Catterall, Miriam. (2002). Analysing qualitative data: Computer software and the market research practitioner. Qualitative Market Research: An International Journal, 5(1), 28-39.

Mäkelä, Kristiina, \& Seppälä, Tomi. (2005). Knowledge sharing in interpersonal cross-border relationships within the MNC, 32nd AIB UK Chapter Conference. Bath.

Marshall, Helen. (2001, July 5-7). Rigour or rigidity? The role of CAQDAS in qualitative research. Paper presented at the Association for Qualitative Research (AQR), Melbourne, Australia.

McGaughey, Sara L. (2004). Writing it up: The challenges of representation in qualitative research. In Rebecca Marschan-Piekkari \& Catherine Welch (Eds.), Handbook of qualitative research methods for international business (pp. 529550). Cheltenham: Edward Elgar.

McGaughey, Sara L. (2007). Narratives on internationalisation: Legitimacy, standards and portfolio entrepreneurs. Cheltenham: Edward Elgar.

Mellor, Nigel. (2001). Messy method: The unfolding story. Educational Action Research, 9(3), 465-484.

Miles, Matthew B., \& Huberman, A. Michael. (1994). Qualitative data analysis: An expanded sourcebook. Thousand Oaks: Sage Publications. 
Orton, James Douglas. (1997). From inductive to iterative grounded theory: Zipping the gap between process theory and process data. Scandinavian Journal of Management, 13(4), 419-438.

Osterloh, Margit, \& Frey, Bruno S. (2000). Motivation, knowledge transfer, and organizational forms. Organization Science, 11(5), 538-550.

Parlett, Malcolm, \& Hamilton, David. (1972). Evaluation as illumination: A new approach to the study of innovatory programs. Occasional paper, Centre for Research in the Educational Sciences, University of Edinburgh.

Patton, Michael Quinn. (1990). Qualitative evaluation and research methods (2nd ed.). Thousand Oaks: Sage.

Peshkin, Alan. (1985). From title to title: The evolution of perspective in naturalistic inquiry. Anthropology \& Education Quarterly, 16(3), 214-224.

Potter, W. James. (1996). An analysis of thinking and research about qualitative methods. Mahwah, NJ.: Lawrence Erlbaum Associates.

Richards, Lyn. (2005). Handling qualitative data - a practical guide. London: Sage Publications.

Shim, J. P., Warkentin, Merrill, Courtney, James F., Power, Daniel J., Sharda, Ramesh, \& Carlsson, Christer. (2002). Past, present, and future of decision support technology. Decision Support Systems, 33(2), 111-126.

Silverman, David. (2005). Instances or sequences? Improving the state of the art of qualitative research. Forum: Qualitative Social Research, 6(3), http://www.qualitative-research.net/index.php/fqs/article/viewArticle/6/13.

Sinkovics, Rudolf R. (2009). Special issue: Qualitative marketing forschung konzeptionelle entwicklungen und methodische trends. der Markt, 48(1), 3-5.

Sinkovics, Rudolf R., Penz, Elfriede, \& Ghauri, Pervez N. (2005). Analysing textual data in international marketing research. Qualitative Market Research: An International Journal, 8(1), 9-38.

Sinkovics, Rudolf R., Penz, Elfriede, \& Ghauri, Pervez N. (2008). Enhancing the trustworthiness of qualitative research in international business. Management International Review, 48(6), 689-714.

Stake, Robert E. (1981). The art of progressive focusing, 65th Annual Meeting of the American Educational Research Association. Los Angeles.

Stake, Robert E. (1995). The art of case study research. Thousand Oaks: Sage Publications.

Strauss, Anselm L., \& Corbin, Juliet M. (1998). Basics of qualitative research: Grounded theory procedures and techniques. Thousand Oaks, CA: Sage Publications.

Suddaby, Roy. (2006). From the editors: What grounded theory is not. Academy of Management Journal, 49(4), 633-642.

Thomson Reuters. (2010). Endnote. Retrieved June, 06, 2010, from http://www.endnote.com

Tranfield, David, Denyer, David, \& Smart, Palminder. (2003). Towards a methodology for developing evidence-informed management knowledge by means of systematic review. British Journal of Management, 14(3), 207-222.

Tranfield, David, \& Starkey, Ken. (1998). The nature, social organization and promotion of management research: Towards policy. British Journal of Management, 9(4), 341-353.

Weitzman, Eben A., \& Miles, Matthew B. (1995). Computer programs for qualitative analysis. Thousand Oaks: Sage Publications.

Wong, Sze-Sze, DeSanctis, Gerardine, \& Staudenmayer, Nancy. (2007). The 
relationship between task interdependency and role stress: A revisit of the job demands-control model. The Journal of Management Studies, 44(2), 284-303.

Yin, Robert K. (2003). Case study research: Design and methods (3rd ed. Vol. 5). Thousand Oaks, CA.: Sage Publications. 


\section{Appendix - Figures and Tables}

Figure 1: A progressive focusing model of the qualitative research process

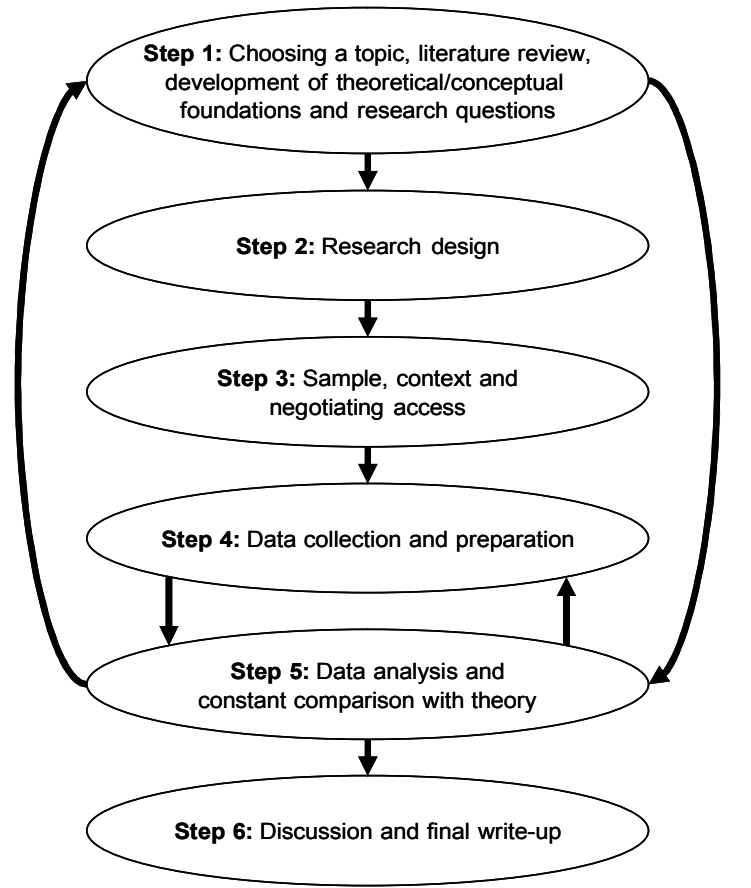


Figure 2: Example of a literature review casebook

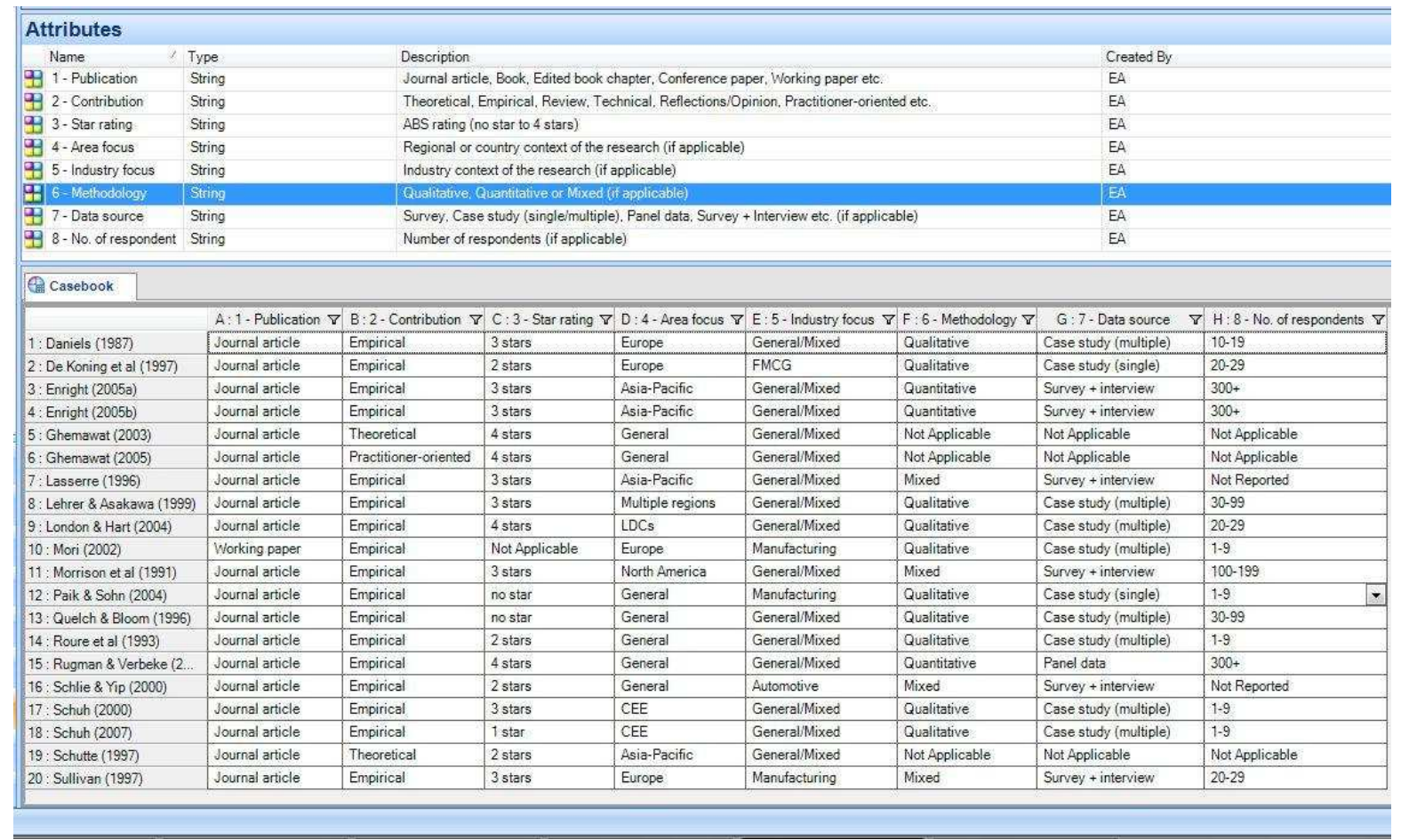


Figure 3: Example of charting cases by attribute value

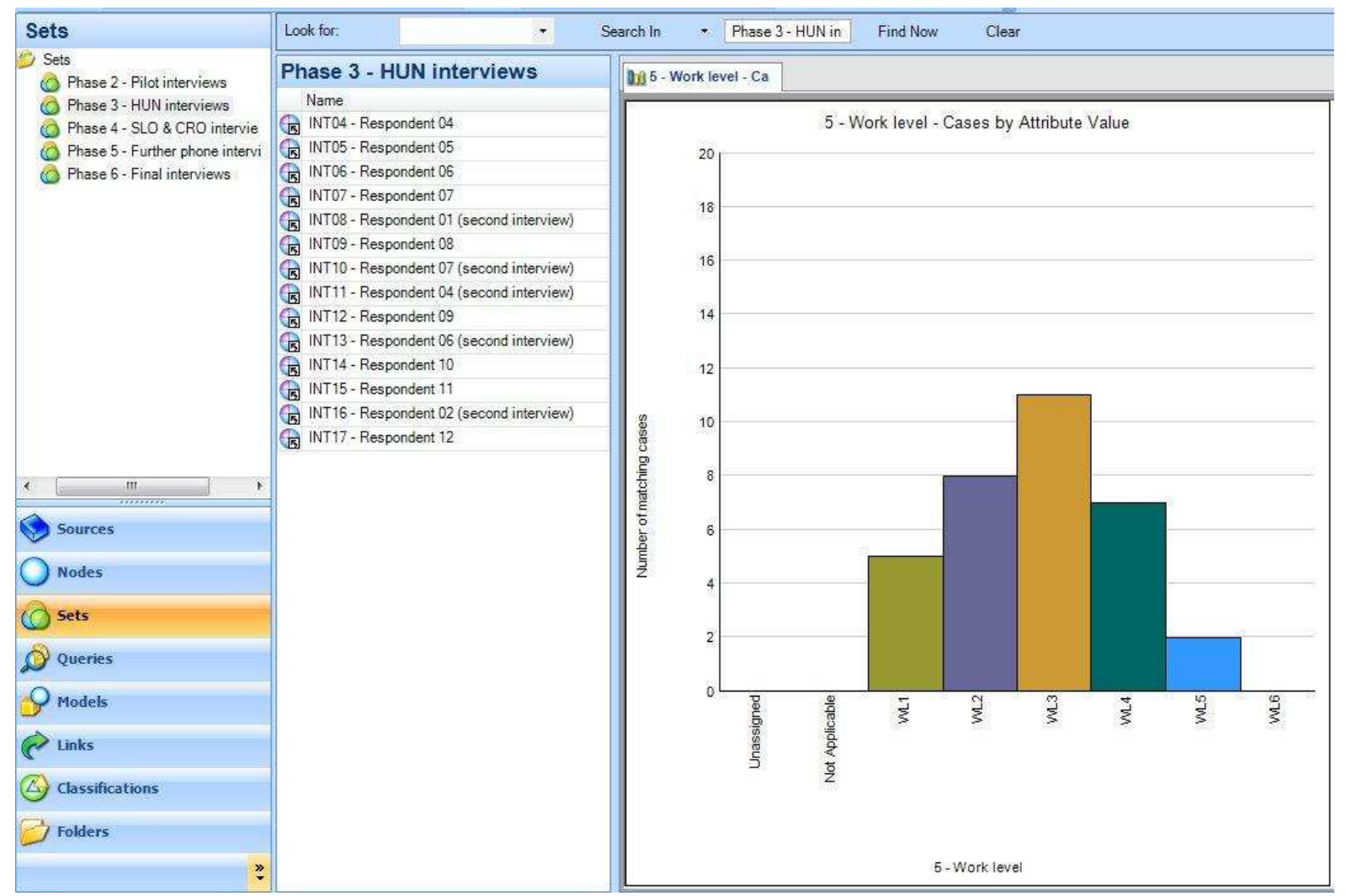


Figure 4: Topic coding schemes $(2006,2007)$ and analytical coding scheme (2008)

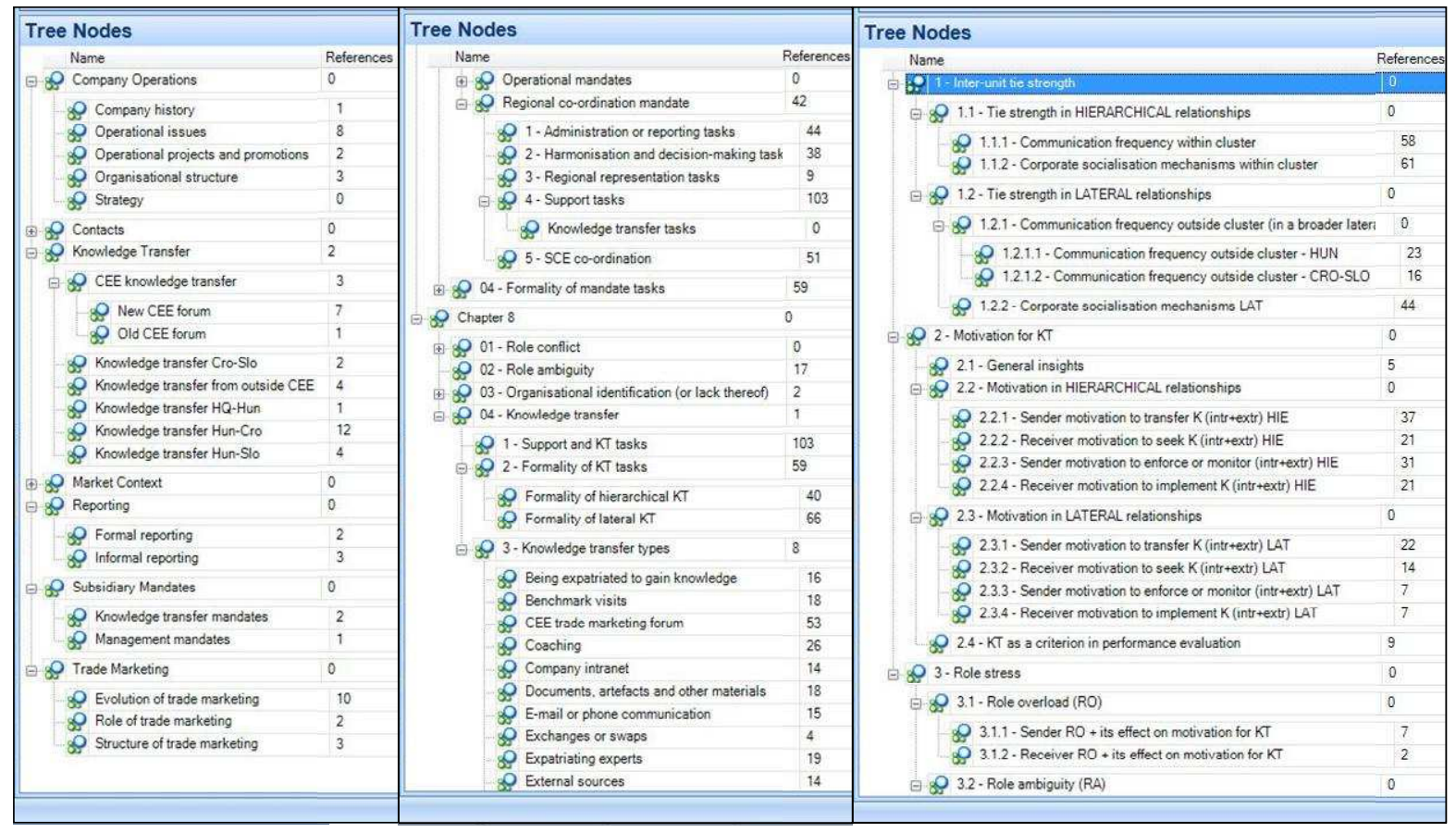

